\title{
Correction to: Rosette plant segmentation with leaf count using orthogonal transform and deep convolutional neural network
}

\author{
J. Praveen Kumar $^{1}$ (D) $\cdot$ S. Domnic ${ }^{2}$
}

Published online: 27 February 2020

(c) Springer-Verlag GmbH Germany, part of Springer Nature 2020

\section{Correction to:}

Machine Vision and Applications (2020) 31:6

https://doi.org/10.1007/s00138-019-01056-2

Unfortunately, the co-author name was incorrectly spelled as "S. Dominic" instead of "S. Domnic" in the original publication. The correct version of author name is updated here.

The original article has been corrected.

Publisher's Note Springer Nature remains neutral with regard to jurisdictional claims in published maps and institutional affiliations.

The original article can be found online at https://doi.org/10.1007/ s00138-019-01056-2.

$\triangle$ J. Praveen Kumar jpraveenkumar5288@gmail.com

1 VIT-AP University, Amaravati, Andhra Pradesh, India

2 National Institute of Technology, Tiruchirappalli, India 